\title{
Commentary: Defeating the stigma of chronic pain
}

De Ruddere and Craig, in their Topical Review [6], describe the stigma applied to and felt by people with chronic pain in a psychosocial context: as deviance from expected behaviour, both in medical settings, where symptoms should be independently verifiable and curable, and in broader social settings, where adults are expected to be autonomous and productive until old age. Stigma is a distressing experience for the target and risks exacerbating social withdrawal, undermining attempts to manage despite pain, and depleting self-esteem [20]. Further, stigma is internalized by people with chronic pain, who may endorse stigmatizing statements along with statements expressing alienation and reporting discrimination [20]. The extent to which stigma was internalized in chronic pain was similar to that in people with severe mental illness [20]. The discrimination is very real: in a study in which students thought they were rating two remote potential exercise partners, shown just in light-dot displays [1] of an outline of the body in movement, the one with pain behavior was rated less warm and less competent than the healthy one, even though students were unaware of the pain. Some hope may be drawn from the finding that one of the ratings concerned pain, and those students who rated one of the two exercise partners as having pain also made less stigmatizing character judgments of that individual.

Perhaps, though, stigma matters most in clinical settings, where it is associated with underassessment and underestimation of pain, with discounting self-report of pain [12], disbelief and suspicion concerning the reality and the extent of suffering [7], and consequent undertreatment (and over-psychologization) of pain [19]. All these processes of dismissing and discounting patients' report affect their encounters, from consultation with a known primary care doctor, to presentation to the Emergency Department with an injury, to 
report of post-operative pain to a ward nurse, and to agitated crying in an elderly person with cognitive impairment [19]. In a study examining social media accounts of chronic pain, many representations on Tumblr (a microblogging and social networking site) described the lack of fit with medical models of pain and described illness as 'excommunication' [11], a term expressing exclusion and deviance from socially accepted norms. There are plenty of studies demonstrating stigma in practice [8]: there are few that attempt to change the beliefs and behaviours of healthcare staff.

The Topical Review by De Ruddere and Craig [6] maps the areas in which research on stigma and pain is seriously lacking. Existing studies are over-reliant on descriptive methods and on self-report in standardized or non-standard forms. They tend to focus on the impact of stigma rather than on causes, mechanisms, or interventions to mitigate stigma and its effects. De Ruddere and Craig are to be congratulated for tackling the difficult topic of possible mechanisms of stigma since, without theory-driven research, as they emphasize, we are likely to make little progress. They hint at some of the broader social forces that put people with chronic pain at a disadvantage, such as the sanctioned deviance of the 'sick role' [16] that recognises the rights of acutely ill people not to fulfil their usual societal roles, but only if they make every effort to acquire and comply with medical advice, a counterproductive pursuit for many with chronic painful disorders. Much of the rhetoric of self-management instantiates this moral dynamic, despite the lack of evidence that it supports patients or enables them to achieve the desired autonomy $[15,18]$.

Invoking evolution as the dynamic that made us as we are now - suspicious of possible freeloaders, doubtful of what we cannot see ourselves but only hear reported - is only part of the picture. Evolution has equipped us with contextual rules of thumb that are so 
fundamental to our experience of the world that we often fail to investigate them. The 'cheater detection mechanism' [2] - the sensitivity to possible exploitation of our resources or common goods - is demonstrated by our difficulty with abstract logical tasks but ease when the same logical problem is expressed in social terms. It is our alertness to possible freeloaders, those who take a common good without earning or deserving what they take, that allows us, in general, to be reasonably altruistic [4]. We make rapid estimations of trustworthiness that, while they generally agree with others' estimations, may have no basis in fact: these, too, affect judgments of authenticity in patients with pain [17]. We are quick to make alliances based on similarity, such as of age, gender, or perceived preferences, but similarity is defined by contrast to outgroups who are different, perhaps in minor ways [5] or even externally allocated such as membership of a temporary team, so that members of the outgroup may be stigmatized and marginalized for trivial reasons. Many of the paradigms used to investigate evolved cognitive, emotional and social biases could usefully be extended to the pain field, whether with human subjects (e.g. [13]) or in silico (e.g. [22]. At an individual level, the proposal of fostering resilience to stigma through emotion regulation in people with chronic pain is promising, aiming to protect them from internalizing or accepting the attributions of stigma, though it leaves stigma itself unchanged. Using clinicians' report of gaps in understanding and in treatment options, De Ruddere and Craig make a good argument for better pain education. But education is not by itself likely to reverse deeply entrenched biases in thinking, adverse automatic judgments, rejecting behaviors, or societal values that underpin them.

Eccleston [9] has defined ours as "an analgesic culture, defined by the dominant belief that pain should be short-lived, diagnostically meaningful, and denote a fixable problem" ( $p 140)$. 
Chronic pain does not fit the model: diagnoses often add little meaning, and most chronic pain cannot be fixed. While basic scientists and clinical researchers may rely on psychology to provide an explanation for what has no concrete evidence, psychology too often proffers psychopathological models remote from biological or social elements of the integrated model. The model of psychosomatic disorder, for instance, applied to pain, has been found dismally inadequate $[3,14]$, and is often stigmatizing [21]. This review of stigma is a welcome psychosocial extension to the normal psychology of pain [10]: there is much more to do. This will require the entire pain community to adopt and promote an integrated biopsychosocial model, explaining it to colleagues and patients alike. Without that, there is little hope of changing understanding of pain in clinical settings, or in the wider community, and therefore of reducing the stigma attached to chronic pain.

\section{References}

1. Ashton-James CE, Richardson DC, Williams ACdeC, Bianchi-Berthouze N, Dekker PH. Impact of pain behaviors on evaluations of warmth and competence. Pain 2014;155:2656-2661.

2. Cosmides L, Tooby J. (1992). Cognitive adaptations for social exchange. In JH Barkow, L Cosmides, J Tooby, editors, The adapted mind: Evolutionary psychology and the generation of culture. Oxford: Oxford University Press, pp. 163-228.

3. Crombez G, Beirens K, Van Damme S, et al. The unbearable lightness of somatisation: a systematic review of the concept of somatisation in empirical studies of pain. Pain 2009;145:31-35.

4. Cronin $\mathrm{H}$. The ant and the peacock: altruism and sexual selection from Darwin to today. Cambridge: Cambridge University Press, 1991.

5. Curry O, Dunbar R. Do birds of a feather flock together? The relationship between similarity and altruism in social networks. Human Nature 2013;24:336-347.

6. De Ruddere L, Craig KD. Understanding stigma and chronic pain: a state of the art review. Pain 2016 (this issue).

7. DeRuddere L, Goubert L, Vervoort T, Prkachin KM, Crombez G. We discount the pain of others when pain has no medical explanation. J Pain 2012;13:1198-1205 
8. Dovidio JF, Fiske ST. Under the radar: how unexamined biases in decision-making processes in clinical interactions can contribute to health care disparities. Amer J Publ Health 2012;102(5):945-52.

9. Eccleston C. Embodied: the psychology of physical sensation. Oxford: Oxford University Press, 2016.

10. Eccleston C. A normal psychology of chronic pain. The Psychologist 2011, 26: 422-425.

11. Gonzalez-Polledo E, Tarr J. The thing about pain: the remaking of illness narratives in chronic pain expressions on social media. New Media \& Society 2014; online pp. 1-19. DOI: $10.1177 / 1461444814560126$

12. Kappesser J, Williams ACdeC. Clinical judgement heuristics: methods and models. Eur J Pain 2013;17(10):1423-4 .

13. Kappesser J, Williams ACdeC. Pain judgements of patients' relatives: examining the use of social contract theory as theoretical framework. J Behav Med 2008;31:309-317.

14. Merskey H. Somatization: or another God that failed. Pain 2009;145:4-5

15. Nicholas MK, Blyth FM. Are self-management strategies effective in chronic pain treatment? Pain Manage 2016;6(1):75-88. doi:10.2217/pmt.15.57

16. Parsons T. Illness and the role of the physician: a sociological perspective. American Journal of Orthopsychiatry. $1951 \mathrm{Jul}$ 1;21(3):452-60.

17. Schäfer G, Prkachin KM, Kaseweter KA, Williams ACdeC. Health care providers' judgments in chronic pain: the influence of gender, trustworthiness and depression. Pain (in press).

18. Stenner P, Cross V, McCrum C, McGowan J, Defever E, Lloyd P, Poole R, Moore AP. Selfmanagement of chronic low back pain: four viewpoints from patients and healthcare providers. Health Psychol Open 2015;1-11. DOI: 10.1177/2055102915615337

19. Tait RC, Chibnall JT, Kalauokalani D. Provider judgments of patients in pain: seeking symptom certainty. Pain Med 2009;10:11-34.

20. Waugh OC, Byrne DG, Nicholas MK. Internalized stigma in people living with chronic pain. J Pain 2014;15(5):550e1-e10.

21. Williams, ACdeC, Cella M. Medically unexplained symptoms and pain: misunderstanding and myth. Current Opinion in Supportive \& Palliative Care 2012;6:201-206. doi: 10.1097/SPC.0b013e328352124f

22. Williams ACdeC, Gallagher E, Fidalgo AR, Bentley PJ. Pain expressiveness and altruistic behavior: an exploration using agent-based modeling. Pain (in press). 